$5 \quad$ Running title: Biodiversity retention in habitat patches

6

7

8

9 A.S.B. (corresponding author) School of Environmental Sciences, University of East Anglia, 10 Norwich, Norfolk, NR4 7TJ, United Kingdom, and Instituto Federal de Educação, Ciência e 11 Tecnologia Farroupilha, Júlio de Castilhos, RS, CP 38, CEP 98130-970, Brazil. Email:

12 buenoas@gmail.com. ORCID: 0000-0001-7416-6626

13

14

\section{Patch-scale biodiversity retention in fragmented landscapes: reconciling the habitat amount hypothesis with the island biogeography theory}

\author{
Anderson Saldanha Bueno and Carlos A. Peres
}




\section{ACKNOWLEDGEMENTS}

We are very grateful to Evanir Damasceno, Tatiane Abreu, Ivana Cardoso and Carla Fonseca for their invaluable field assistance. We also thank Alexander Lees for helping with bird identification, the staff at Reserva Biológica do Uatumã for logistical support, CEMAVE for supplying bird rings, and Lenore Fahrig and the anonymous referees for their valuable comments on the manuscript. This study was funded by the Rufford Foundation (grant 17715-1), Reserva Biológica do Uatumã (ICMBio), University of East Anglia, and a NERC/UK grant (NE/J01401X/1) awarded to CAP. ASB is funded by a PhD studentship (grant 200463/2014-4) from Conselho Nacional de Desenvolvimento Científico e Tecnológico (CNPq) - Brazil. 
Aim: To test whether the species richness of understorey insectivorous birds on forest islands induced by a major hydroelectric dam is best explained by either the island biogeography theory (IBT) or the habitat amount hypothesis (HAH). Given the low dispersal ability of the focal species group and the hostile water matrix, we predict that the species richness will be predominantly driven by an island effect as posited by the IBT, rather than a sample area effect as posited by the HAH.

Location: Forest islands within the Balbina Hydroelectric Reservoir, central Brazilian Amazonia.

Taxon: Birds.

Methods: We mist-netted birds at 33 forest islands (0.63-1,699 ha), totalling 874 individuals of 59 species. The size of the local landscape used to calculate the habitat amount was determined by a multi-scale analysis in which buffers around mist-net lines ranged from 50 to $2,000 \mathrm{~m}$. We applied four tests to examine whether the species richness on forest islands is predominantly driven by either an island effect (island size) or a sample area effect (habitat amount).

Results: From the four tests applied, one was consistent with an island effect, two were regarded as inappropriate to test the $\mathrm{HAH}$, and one could not be adequately addressed due to island size being highly correlated with habitat amount in the local landscape (200-m buffer).

Main conclusions: Some of the proposed ways of testing the HAH may lead to misleading conclusions. The relative importance of island size in determining the species richness of understorey insectivorous birds on forest islands is higher than that of surrounding habitat amount, thereby providing stronger support for IBT. We propose a conceptual framework, based on the degree of matrix permeability and species dispersal ability, to determine to what extent a patch- or landscape-centric worldview in landscape ecology provides the most appropriate framework to assess the effects of habitat fragmentation on biodiversity.

Key-words: Amazonia, habitat amount hypothesis, habitat fragmentation, habitat loss, insularization, island biogeography theory, SLOSS, species richness, species-area relationship, tropical forest 


\section{INTRODUCTION}

MacArthur \& Wilson's (1967) island biogeography theory (hereafter, IBT) has been widely applied as a paradigmatic conceptual framework in habitat fragmentation ecology, implying that habitat patches are analogous to oceanic islands surrounded by a hostile matrix (Haila, 2002; Laurance, 2008). However, such analogy has been repeatedly challenged since IBT does not account for many factors operating in fragmented landscapes (Laurance, 2008; Wiens, 2008), which were later incorporated into a landscape ecology framework (Haila, 2002). For example, species move among suitable habitat patches as a function of varying degrees of terrestrial matrix permeability (Powell et al., 2013), indicating that habitat patches exert weaker boundaries to local populations and their derivative assemblages compared to oceanic islands. If habitat patches fail to behave as discrete spatial units, the universally celebrated species-area relationship (hereafter, SAR) - which is widely observed in fragmented landscapes (Matthews et al., 2016) - may be governed at spatial scales larger than that of island effects driven by habitat patch size.

With this in mind, Fahrig (2013) proposed the habitat amount hypothesis (hereafter, $\mathrm{HAH}$ ), which posits that (1) habitat patches are not discrete spatial units, and (2) the habitat surrounding any given patch is the main source of immigrants. The underlying mechanism of SARs in fragmented landscapes is therefore predicted to be the sample area effect, rather than the island effect. Accordingly, sample sites within larger habitat patches harbour more species because they are also associated with a greater amount of surrounding habitat. Meanwhile, sample sites associated with the same amount of landscape-scale habitat should harbour the same number of species, regardless of patch size (Fig. 7 in Fahrig, 2013). Such notion implies that conservation efforts should primarily focus on increasing the overall habitat amount (i.e. the proportion of habitat in the landscape) without necessarily considering its spatial arrangement (i.e. size and isolation of individual habitat patches) (Seibold et al., 2017).

The generalisation of the HAH was initially criticised since its application was considered to be restricted to small-scale landscapes containing large habitat amounts (Hanski, 2015), although the HAH was yet to be tested (Fahrig, 2015). Recent empirical studies carried out in a variety of natural (e.g. forest fragments, fluvial islands, calcareous grasslands) and experimental fragmented landscapes (e.g. dead-wood microhabitats, moss fragments), across a wide range of taxonomic groups (e.g. small and arboreal mammals, birds, vascular plants, saproxylic beetles, and micro-arthropods), have either supported (Melo et al., 2017; Rabelo et al., 2017; Seibold et al., 2017) or refuted (Evju \& Sverdrup-Thygeson, 2016; Haddad et al., 2016; Torrenta \& Villard, 2017) the HAH. Therefore, further empirical studies are needed to appraise the degree to which the HAH can be generalised to different landscape scenarios and taxonomic groups (Rabelo et al., 2017). 
The IBT and HAH were originally developed within a context of oceanic islands (MacArthur \& Wilson, 1967) and habitat patches within terrestrial landscapes (Fahrig, 2013), respectively. These two landscape scenarios may be seen as extremes along a continuum. In a global synthesis, Matthews et al. (2016) showed that $z$-values of SARs are higher in true islands than in habitat patches. They also reported gradients in $z$-values ranging from inland water-body to oceanic islands, and from forest to mountaintop habitat patches. Hence, the magnitude of island effects is context-dependent regarding the type of matrix surrounding habitat patches (Prugh et al., 2008). Patterns of species richness in intermediate landscape scenarios, such as inland water-body islands and mountaintops, could therefore be explained by either IBT or HAH.

The HAH was erected under the assumption that species perceive the wider macrohabitat mosaic as functionally connected (Fahrig, 2013). Matrix permeability, as measured by the structural similarity between habitat patches and any surrounding matrix (Prevedello \& Vieira, 2010), along with inherent differences in species dispersal ability (Lees $\&$ Peres, 2009), would then determine whether species use their habitat primarily at the patch- or landscape-scale. Accordingly, we hypothesise that patterns of species richness in fragmented landscapes can be better explained under either the HAH if species exhibit high levels of dispersal ability across a permeable matrix, or the IBT if species exhibit low dispersal ability across a hostile matrix.

Here, we examined whether the HAH can be extended to anthropogenic archipelagic landscapes using the number of understorey insectivorous bird species on forest islands induced by a large hydroelectric dam in central Brazilian Amazonia. We focused on understorey insectivorous birds because they are particularly vulnerable to forest loss and fragmentation (Powell et al., 2015), and exhibit low dispersal ability through non-forest matrix habitats (Sekercioglu et al., 2002; Laurance et al., 2004). We show that the number of understorey insectivorous bird species on forest islands is best explained by an island effect, which is consistent with the IBT. Moreover, we propose a conceptual framework, based on the degree of matrix permeability and species dispersal ability, to determine which point along the continuum between a patch- and landscape-centric worldview in fragmentation ecology - represented here by either IBT or HAH - provides the most appropriate guiding framework for biodiversity studies in fragmented landscapes.

\section{MATERIALS AND METHODS}

\section{Study area}

This study was carried out within the Balbina Hydroelectric Reservoir (BHR) in central Brazilian Amazonia (140’ S, 5940’ W; Fig. 1). The BHR spans ca. 300,000 ha and 
was formed by the damming of the Uatumã River in 1987 (Fearnside, 2016), creating over 3,500 land-bridge islands of variable size (range $=0.2-4,878 \mathrm{ha}$ ), which are surrounded by a vast water reservoir often containing dead tree snags rising above the water level (Benchimol $\&$ Peres, 2015a). To offset the environmental impacts of the dam, the left bank of the former Uatumã River, including all islands, became strictly protected by the 940,358-ha Uatumã Biological Reserve (IUCN category Ia), the largest of its category in Brazil (Fig. 1).

The vegetation is comprised primarily of submontane dense ombrophilous (terrafirme) forest, although igapó forest subjected to seasonal flooding formerly occurred along the margins of the Uatumã River before damming. Forest structure varies among islands due to both island size and associated edge-mediated disturbance: smaller islands are species-poor and dominated by pioneer tree species, whereas larger islands are species-rich and contain a higher dominance of large-seeded canopy tree species (Benchimol \& Peres, 2015a). According to the Köppen classification, the climate is equatorial fully humid (Af), with mean annual precipitation and temperature of $2,464 \mathrm{~mm}$ and $26.5^{\circ} \mathrm{C}$, respectively (Alvares et al., 2013).

\section{Sampling design}

We selected 33 forest islands within the BHR, ranging in size from 0.63 to $1,698.84$ ha. Sixteen islands were on the left bank, whereas 17 islands were on the right bank (Fig. 1). The combined study meta-landscape encompassed 177,720 ha where sample sites were spaced apart by an average distance of $27.9 \mathrm{~km}(\mathrm{SD}=15.0 \mathrm{~km}$; range $=2.0-68.4 \mathrm{~km})$.

We surveyed birds using mist nets $(12 \times 2.5 \mathrm{~m}$, Ecotone $1016 / 12)$ from July to December in two consecutive years (2015 and 2016). We placed 16 mist nets end-to-end in the understorey along a continuous near-linear net-line ( $c a .200 \mathrm{~m})$ whenever possible, but used a cross-shaped net-line design on islands smaller than 4 ha, thereby ensuring the same sampling effort across all 33 surveyed islands. Herein, each mist-net line corresponds to one sample site. Mist nets were operated from 06:00 to 15:00 $\mathrm{h}$ for two days at each site each year, resulting in a total sampling effort of 19,008 net-hours (16 mist nets $\times 9$ hours $\times 2$ days $\times 2$ years $\times 33$ sites). To avoid double-counting, we ringed birds with coded aluminium rings and excluded recaptures. Rings were provided by the Brazilian National Center for Bird Conservation and Research (CEMAVE) under research permits SISBIO 49068 and CEMAVE 3984.

\section{Response variable and species group}


We used the number of species of understorey insectivorous birds as the response variable, and limited our analysis to forest species because the habitat type (i.e. forest) must be appropriately defined for the focal species group (Fahrig, 2013). We defined forest species as those classified as having 'medium' or 'high' levels of forest dependency (sensu BirdLife International, 2018), and insectivorous species as those classified under the 'invertebrate' dietary category (sensu Wilman et al., 2014). The only forest insectivorous species omitted from the analysis was the Amazonian Pygmy-Owl (Glaucidium hardyi) because surveys were diurnal, and this species is nocturnal (Wilman et al., 2014). Since understorey mist nets primarily capture understorey birds and occasionally those that walk on the ground or forage at forest strata higher than $2.5 \mathrm{~m}$ (Karr, 1981), we considered all species captured as understorey birds to avoid misinterpretation.

\section{Predictor variables}

We extracted data on island size and habitat amount for all 33 sample sites using a classified image (Collection 2, 2015, Amazon) derived from 30-m resolution LANDSAT imagery downloaded from the Brazilian Annual Land Use and Land Cover Mapping Project (available at http://mapbiomas.org). To do so, we used the QGIS software (QGIS Development Team, 2016) and the LecoS plugin (Jung, 2016). Island size corresponds to the total forest area (in hectares) within an island, and habitat amount corresponds to the percentage of forest cover within a given surrounding landscape at varying scales. In extracting the predictor variables, only 'dense forest' (pixel value 3) was defined as forest, because other pixel values effectively represent either heavily degraded forests or non-forest land cover types.

\section{Data analysis}

Scale of effect

Species-landscape relationships are strongly affected by the scale at which landscape attributes are measured (Jackson \& Fahrig, 2015). We therefore employed a multi-scale analysis to determine the 'scale of effect' - the landscape scale at which the relationship between the number of species and habitat amount peaks (Jackson \& Fahrig, 2015). We defined the scale of effect as the 'local landscape' for understorey insectivorous birds at the Balbina forest archipelago. Our multi-scale analysis examined 40 different buffer sizes around sample sites (i.e. mist-net lines), ranging from 50 to 2,000 $\mathrm{m}$ at $50-\mathrm{m}$ intervals. The smallest landscape scale $(50 \mathrm{~m})$ corresponds to the average between the reluctance of Amazonian understorey birds to cross forest clearings as narrow as $30 \mathrm{~m}$ (Laurance et al., 2004) and an assemblage-wide avian gap-crossing ability of up to $70 \mathrm{~m}$ (Lees \& Peres, 2009). 
The largest landscape scale $(2,000 \mathrm{~m})$ includes those frequently used in avian fragmentation studies (Jackson \& Fahrig, 2015; Morante-Filho et al., 2015; Aurélio-Silva et al., 2016). For this analysis, we included all 33 surveyed islands and log-transformed the response and predictor variables $\left(\log _{10} \mathrm{x}+1\right)$.

\section{IBT vs. HAH}

The number of species in fragmented landscapes can be explained by either patch size (e.g. Torrenta \& Villard, 2017) or habitat amount (e.g. Melo et al., 2017), which represent two worldviews in assessing the total area of suitable habitat. This means that the iconic SAR (Rosenzweig, 1995) holds true regardless of its spatial drivers (patch size or habitat amount), but that the underlying mechanism may be either the island effect driven by patch size as predicted by the IBT, or the sample area effect driven by habitat amount as predicted by the HAH (Fahrig, 2013). We applied four tests to determine whether the IBT or the HAH is the most appropriate theoretical framework to explain the number of understorey insectivorous bird species on forest islands within the BHR.

\section{Test 1: Multiple linear regression}

We used multiple linear regression analysis to examine the independent effects of island size and habitat amount in the local landscape on species richness. This method allows one to estimate how much of the variation in the response variable (i.e. number of species) can be attributed solely to a predictor variable (e.g. island size), once the effects of another predictor (e.g. habitat amount) are controlled for (Legendre \& Legendre, 1998).

An effect of island size, rather than one of habitat amount, would provide support for IBT, whereas the reverse would provide support for HAH (Fig. 2). The response and predictor variables were $\log$-transformed $\left(\log _{10} \mathrm{x}+1\right)$ prior to analysis. The predictor variables were also standardised (mean $=0, \mathrm{SD}=1)$ to allow comparison of regression slopes. Finally, we examined the strength of correlation values between island size and habitat amount across the entire spectrum of 40 landscape scales (50-2,000 m) to assess the suitability of the multiple linear regression test.

\section{Test 2: Z-values}

We used the logarithmic form of the SAR (type IV curve sensu Scheiner, 2003) to fit simple linear regression models (Rosenzweig, 1995) for islands surrounded by either low 
habitat amounts (up to $c a .50 \%$ of the landscape; Morante-Filho et al., 2015) or high habitat amounts, according to the following equation:

$$
\log _{10}(S+1)=z \times \log _{10}(A+1)+\log _{10}(c),
$$

where $S=$ number of species, $z=$ regression slope, $A=$ island size, $c=$ regression intercept. To assess whether the $z$-values derived from either SARs were significantly different $(p<$ 0.05), we performed an ANCOVA model with habitat amount (low or high) as an independent categorical variable. To support the IBT, the SAR for islands with low habitat amounts should have a higher $z$-value than those with high habitat amounts (Fig. 2). Conversely, $z$-values should be statistically equivalent to support the HAH (Fig. 2).

\section{Test 3: Species accumulation curves}

We compared the cumulative number of species on all 33 surveyed islands ordered according to both increasing (small-to-large) and decreasing (large-to-small) island sizes (Quinn \& Harrison, 1988), which may lead to three possible outcomes. First, the small-tolarge accumulation curve lies below the large-to-small, supporting IBT (Fig. 2). Second, the curves overlap, supporting HAH (Fig. 2). Third, the small-to-large accumulation curve lies above the large-to-small, supporting neither IBT nor HAH.

\section{Test 4: Extrapolation of SAR}

We fit a SAR model (see Test 2: Z-values) to all 33 surveyed islands. We further extrapolated the number of species to a hypothetical island containing the area $(+1)$ of all 33 surveyed islands combined (7,841.4 ha), and compared the overall number of species observed across surveyed islands with the extrapolated value (Yaacobi et al., 2007). Compared with the extrapolated value, a lower observed number of species would support IBT (Fig. 2); a statistically equivalent number, HAH (Fig. 2); a higher number, neither IBT nor HAH.

\section{RESULTS}

We captured a total of 874 individual understorey insectivorous birds representing 59 species, 49 genera and 19 families across all 33 sample sites (see Table S1 in Supporting Information). The number of individuals per island ranged from 0 to 84 (26.5 \pm 23.4$)$, and the number of species from 0 to $27(8.8 \pm 7.5$; see Table $S 2)$. 
The correlational peak between the number of species and habitat amount (i.e. the scale of effect) occurred at 200-m buffers around sample sites ( $r=0.873$; see Fig. S1), thereby corresponding to the local landscape for understorey insectivorous birds at the Balbina forest archipelago. The fact that this local landscape is intermediate between the smallest and the largest landscape scales examined here indicates that our multi-scale analysis included the true scale of effect (Jackson \& Fahrig, 2015). Therefore, habitat amount is defined as the percentage of forest cover only within 200-m buffer local landscapes for all subsequent analyses.

Test 1: Multiple linear regression

A multiple linear regression model including island size and habitat amount showed that both predictor variables were strongly and positively related to the number of species $\left(R^{2}\right.$ $=0.80, p<0.001)$. Partial regressions also showed that habitat amount had a slightly better fit and higher regression slope than island size (see Fig. S2), which in itself would lend more support for HAH than IBT. However, island size and habitat amount were positively correlated across the entire range of 40 landscape scales examined and peaked exactly at the scale of effect (200-m buffer; see Fig. S3). Due to the high collinearity between predictors ( $r$ $=0.857$ ), regression coefficients could change depending on the random component in the response variable (Legendre \& Legendre, 1998), thereby precluding us from raising any conclusions derived from Test 1.

Test 2: $Z$-values

The species-area relationship for islands surrounded by low habitat amounts $(<55 \%)$ had a statistically higher $z$-value $(0.747)$ than islands surrounded by high habitat amounts (> $70 \% ; 0.311)$, as shown by an ANCOVA test ( $p=0.009$; Fig. 3 ). This outcome supports an island effect, rather than solely a sample area effect (Fahrig, 2013), thereby lending stronger support for IBT.

Test 3: Species accumulation curves

Species accumulation curves did not overlap whether sampling sites were ordered according to increasing (small-to-large) or decreasing (large-to-small) island sizes. The small-to-large curve lay above the large-to-small curve (Fig. 4), which contradicts both IBT and $\mathrm{HAH}$. 
Test 4: Extrapolation of SAR

We observed a larger number of species $(59+1)$ across all 33 surveyed islands than that extrapolated (55.2) to a hypothetical island containing the area $(+1)$ of all surveyed islands combined (7,841.4 ha). However, the difference between the observed and extrapolated number of species was not significant (Fig. 5), which lends support for HAH.

\section{DISCUSSION}

Compared to the $\mathrm{HAH}$, there was more evidence giving support to the IBT in explaining the number of understorey insectivorous bird species within Amazonian forest islands in one of the largest hydroelectric reservoirs on Earth. Considering the four tests applied, Test 2 ( $z$-values) was consistent with an island effect as posited by the IBT, Tests 3 (SACs) and 4 (extrapolation of SAR) were regarded as inappropriate to test the HAH (see below), and Test 1 (multiple linear regression) could not be adequately addressed due to a prohibitively high correlation between island size and habitat amount at the local landscape. Since both an island effect (e.g. Evju \& Sverdrup-Thygeson, 2016) and a sample area effect (e.g. Rabelo et al., 2017) may explain patterns of species richness in fragmented landscapes, the key question becomes which of these two theoretical frameworks provides the best fit to different scenarios in 'real-world' fragmented landscapes. This question has critical implications to biodiversity conservation strategies since empirical evidence primarily supporting IBT would imply a management focus on the spatial arrangement of remaining habitat patches, whereas support for HAH would imply a management strategy focused on retaining the maximum overall amount of habitat regardless of its configuration (Seibold et al., 2017).

The independent effects of predictor variables may be disentangled using statistical methods such as multiple regression analysis. However, as the degree of collinearity between predictor variables increases, the accuracy in determining their independent effects decreases, particularly above a high threshold $(r>0.7)$ from which parameter estimates begin to be severely distorted in regression-type analyses (Dormann et al., 2013). In our set of sample sites, the highest correlation between island size and habitat amount occurred exactly at the scale of effect (i.e. 200-m buffer; $r=0.857$ ), which precluded us from directly testing the predictions of the HAH. Ideally, patch size and habitat amount should be either orthogonally independent or negatively correlated (Fig. 7 in Fahrig, 2013). However, the pervasive positive correlation between habitat patch size and habitat amount in landscapes worldwide is the rule rather than the exception (Fahrig, 2003), and this correlation becomes even stronger and more ubiquitous for smaller local landscapes (Rabelo et al., 2017). For instance, island 
size and habitat amount were more likely to be independent in our study system at larger scales, well beyond a demographically realistic local landscape for our focal species group.

The scale of effect is indeed unlikely to be known before sampling design is established, thereby a multi-scale analysis is necessary to determine the local landscape (Fahrig, 2013). This implies that sample sites selected a priori to control for the positive correlation between patch size and habitat amount may fail to achieve this goal if the size of the local landscape is different than initially thought. To illustrate this, consider a set of sample sites where the size of the focal habitat patches increases while the amount of habitat remains constant (Fig. 6). If the size of the local landscape derived from a multi-scale analysis is found to be half of that defined a priori, patch size and habitat amount will be positively correlated (Fig. 6). Therefore, directly testing the HAH under its main assumptions is expected to be less feasible if the scale of effect is small or not known a priori. Despite these shortcomings, there are alternative ways of testing the HAH (Fahrig, 2013).

First, if patch size per se does not affect the number of species, as predicted by the $\mathrm{HAH}, z$-values derived from species-area relationships are expected to be the same in landscapes with either low or high habitat amounts (Fig. 2). We showed that the $z$-value for islands at landscapes isolated by low habitat amounts $(<55 \%)$ is statistically higher than that at landscapes connected by high habitat amounts (> 70\%; Fig. 3), which contradicts a prediction of the HAH. Such a difference could be attributed to the selected cut-off (55\%) that distinguishes low from high habitat amounts. To test whether the difference in $z$-values is sensitive to this threshold, we reran the $z$-value test using different cut-offs for habitat amount $(54 \%, 50 \%, 48.5 \%, 45 \%, 43.1 \%, 30 \%$; see Supporting Information). The differences in $z-$ values held true except when the species-area relationship for islands surrounded by low habitat amounts was not significant. Since all islands were smaller than 10 ha for the lower cut-offs $(\leq 45 \%)$, the lack of a relationship may be explained by the small island effect (i.e. for small islands, the variation in island size does not affect the number of species; Lomolino \& Weiser, 2001). In sum, forest islands surrounded by low habitat amounts had a steeper decline in species richness as a function of island size reduction (i.e. higher $z$-value) than those surrounded by high habitat amounts whenever the SAR models were significant.

The difference between $z$-values is attributed to an island effect, which is consistent with the IBT (Fahrig, 2013). Accordingly, larger and less isolated islands are more speciesrich than smaller and more isolated islands because the former experience lower extinction (area effect) and higher colonisation rates (distance effect) (MacArthur \& Wilson, 1967). Thus, if islands within their local landscapes were functionally connected as assumed by the $\mathrm{HAH}$, the number of immigrants reaching focal islands would mainly depend on the amount of habitat surrounding those islands (sample area effect), thereby compensating species declines through rescue effects (Fahrig, 2013; see Seibold et al., 2017). 
Second, the species accumulation curves (SACs) from either small to large patches or from large to small patches (Fig. 2) should roughly coincide to support HAH since this is caused by a sample area effect, meaning that the long-celebrated dichotomy between a Single Large Or Several Small patches (SLOSS) should harbour a similar number of species. Alternatively, a faster accumulation in the number of species from large to small patches, compared to that from small to large patches, would be attributed to an island effect (IBT). The cumulative number of understorey insectivorous bird species at the Balbina forest archipelago rose faster from small to large patches than from large to small ones, which supports neither IBT nor HAH.

The fact that several small patches (islands) apparently harboured more species than a single large patch (Fig. 4) is consistent with the literature (Fahrig, 2017). However, we did not find support for several possible explanations for this pattern at the Balbina forest archipelago. First, we strictly focused on forest species implying that the pattern was not confounded by the inclusion of disturbance-adapted species, which would increase the overall number of species across small patch sites (Lovei et al., 2006). Second, habitat heterogeneity, regarding vegetation structure in Amazonian terra firme forests, is associated with elevation (Castilho et al., 2006), below-ground vertical distance to the water table (Schietti et al., 2014) and horizontal distance to perennial streams (Drucker et al., 2008). Thus, several small patches could harbour more species than a single large patch if they covered wider topographic and hydrologic gradients, resulting in higher levels of habitat heterogeneity (Báldi, 2008). However, our islands consist of upland habitat remnants resulting from hilltop terrains of the once continuous forest. As such, they span similar elevations and streams were missing from all but two very large islands (Beco do Catitu and Mascote). As a result, surveyed islands shared relatively low levels of intra-patch habitat heterogeneity regarding closed-canopy forest structure. Third, the Balbina islands are isolated by a hostile water matrix which likely hinders the dynamic of colonisation and extinction (Palmeirim et al., 2017), particularly for species that are unable to either cross wide gaps or use dead tree snags as stepping stones. Indeed, the disappearance of understorey insectivorous birds from forest fragments has been largely attributed to dispersal limitation (Sekercioglu et al., 2002), which along with a severely hostile water matrix explain patterns of bird species occupancy on forest islands (Moore et al., 2008). The relatively small local landscape threshold (200-m buffer) for understorey insectivorous birds at the Balbina forest archipelago provides additional evidence of such dispersal limitation (Jackson \& Fahrig, 2012).

The most likely explanation for the observed SACs (Fig. 4) relies on a bias associated with this method. In a SLOSS-type study, Gavish et al. (2012) compared four methods to examine the effects of habitat loss and fragmentation on the species richness of spiders. They concluded that only SACs (Quinn \& Harrison, 1988) should be avoided as this method was biased towards detecting more species in several small habitat patches than in a single large 
patch. This occurs because the method is sensitive to sampling intensity (i.e. proportion of patch area that is sampled), which could lead to an apparent higher number of species in small but more intensively sampled patches (Gavish et al., 2012). Since the proportion of the island area we sampled in smaller islands was immensely higher than in larger islands, the result of the SACs is likely to be misleading. Moreover, the pattern of SACs was inconsistent with the HAH even in an experiment designed to decouple the independent effects of patch size and habitat amount on saproxylic beetles whose revealed strong support for $\mathrm{HAH}$ (Seibold et al., 2017).

Third, the extrapolation of the SAR model (Yaacobi et al., 2007) suggests that several small islands did not harbour more understorey insectivorous bird species than a single large island containing the same aggregate area of several small islands (Fig. 5). This result is presumably consistent with the HAH (Fahrig, 2013; MacDonald et al., 2018). However, had this method been suitable to test the HAH, oceanic archipelagos should harbour fewer species than that predicted by the extrapolation of SAR models derived from their constituent islands. Indeed, observed and extrapolated values of species richness for most oceanic archipelagos are statistically the same (75\% to $95 \%$ of 40 case studies; Santos et al., 2010). Collectively, this means that neither SACs nor an extrapolation of SAR models seem to be reliable methods to test the HAH.

Testing the HAH is by no means a trivial task for two main reasons. First, as a general rule, habitat patch size and habitat amount tend to be positively correlated (Fahrig 2003). However, these two predictors should be either largely orthogonal or negatively correlated to properly test predictions derived from the HAH (Fig. 7 in Fahrig, 2013). Depending on the landscape, this constraint may however be overcome if the scale of effect (sensu Jackson \& Fahrig, 2015) is known prior to the establishment of the experimental design. Second, species assemblages are comprised of species with varying degrees of dispersal ability, although within some groups, such as understorey insectivorous birds, such a trait is broadly similar across species (Laurance et al., 2004). Thus, the scale of effect for a given species assemblage will result from a combination of species with either lower or higher dispersal ability (Lees \& Peres, 2009). Therefore, we believe the most robust way forward in testing the HAH would be to focus on individual species (Hanski, 2015) whose dispersal ability through the matrix (i.e. landscape vagility) is known a priori and derived from in situ studies (e.g. Awade \& Metzger 2008). 
We can reasonably expect that local assemblage structure is primarily governed by patch-level characteristics in a hypothetical situation in which species seldom if ever exit the patch, due to low dispersal ability, low matrix permeability, or both (Moore et al., 2008). Conversely, landscape-level characteristics should matter most in a hypothetical situation in which species often move among patches within the local landscape, due to high dispersal ability, high matrix permeability, or both (Walter et al., 2017). Hence, the degree to which either a patch- or landscape-centric worldview is most pertinent in fragmentation ecology studies should be determined by the species vagility within the local landscape, which is largely a combination of matrix permeability (a landscape attribute) and dispersal ability (a species trait) (Fig. 7). Accordingly, increasing support for IBT should be expected for a species assemblage with low dispersal ability in patches surrounded by an impermeable matrix (Fig. 7c; this study; Palmeirim et al., 2017). Conversely, increasing support for HAH would be expected for a species assemblage in which high dispersal ability is prevalent and habitat patches are surrounded by a permeable matrix (Fig. 7b; Melo et al., 2017). Under intermediate scenarios (Fig. 7a and 7d), the most appropriate theoretical framework - IBT or $\mathrm{HAH}$ - would depend on the relative contributions of matrix permeability and species dispersal ability. For instance, support for HAH would be expected if species successfully move among patches even if they are surrounded by an impermeable matrix (Fig. 7a; StorckTonon \& Peres, 2017), whereas support for IBT would be expected if species fail to move among patches even if they are surrounded by a relatively permeable matrix (Fig. 7d; Munguía-Rosas \& Montiel, 2014).

A recent empirical study testing the HAH (MacDonald et al., 2018) provides further support for our conceptual framework. Accordingly, the inclusion of highly mobile species in the species pool led to stronger support for HAH in explaining the number of butterfly species on islands within a natural archipelagic landscape (Fig. 7a), whereas excluding highly mobile species led to stronger support for IBT (Fig. 7c). Our conceptual framework also accounts for dynamic matrix habitats that change over time. As such, for a given forest landscape dominated by a regenerating vegetation matrix that accumulates aboveground phytomass, a patch-centric approach should be gradually replaced by a landscape-centric approach as the matrix becomes more permeable, ultimately enhancing species vagility of even the most sedentary species (Powell et al., 2013). The Biological Dynamics of Forest Fragments Project (BDFFP) in central Brazilian Amazonia is an iconic example of a dynamic tropical landscape, in which a cattle pasture matrix surrounding primary forest fragments has been fully replaced by an ageing secondary forest over the past ca. 35 years (Stouffer et al., 2011). As the structural contrast between forest fragments and their adjacent matrix decreases, forest species can resume movements between forest fragments (Stouffer et al., 2011), exploit newly available matrix resources (Blake \& Loiselle, 2001), and incorporate 
classification of the landscape into either habitat or non-habitat is at best misleading (Stouffer et al., 2006), and a landscape-centric approach would be most appropriate.

At the Balbina forest archipelago, the structural contrast between habitat patches (forest islands) and the matrix (open-water) could not be greater, and is aggravated by the fact that matrix recovery, by definition, cannot occur within hydroelectric reservoirs with stable water levels. Such harsh landscape scenario restricts populations of species with low dispersal ability to fewer islands compared to species that can traverse the matrix. Indeed, the inherent swimming capacity - a measure of dispersal ability on open-water - of large vertebrate species at the Balbina forest archipelago is positively related to species island occupancy (Benchimol \& Peres, 2015b). Based on both patch- and landscape-scale predictors, that study also found island size to be the single best predictor of island occupancy for most species. Likewise, island size was a powerful predictor of species richness of terrestrial and arboreal vertebrates $\left(r^{2}=0.910\right.$, Benchimol \& Peres, 2015c), birds $\left(r^{2}=0.808\right.$, Aurélio-Silva et al., 2016), lizards ( $r^{2}=0.870$, Palmeirim et al., 2017) and frogs $\left(r^{2}=0.891\right.$, Lima et al., 2015) within Amazonian forest archipelagos. Given this bulk of evidence showing a strong island size effect on species richness, a patch-centric approach (IBT) is likely to be the most appropriate in true archipelagic landscapes. Nevertheless, species with high dispersal ability (e.g. orchid bees, Storck-Tonon \& Peres, 2017; butterflies, MacDonald et al., 2018) may still be able to cross hostile expanses of water, which would justify a landscape-centric approach (HAH).

\section{CONCLUSIONS}

We tested the habitat amount hypothesis $(\mathrm{HAH})$ under one extreme of the continuum of matrix permeability and species dispersal ability (Fig. 7c) and found stronger support for the island biogeography theory (IBT). Meanwhile, we hypothesise that stronger support for HAH is expected under the opposite extreme of this continuum (Fig. 7b), and to either IBT or HAH under intermediate scenarios (Fig. 7a and 7d). This notion implies that most species responses to habitat fragmentation lie somewhere along these extremes. Hence, IBT and HAH should not be seen as a mutually exclusive dichotomy, but instead a continuum in explaining patterns of species retention in habitat patches. The conceptual framework we propose (Fig. 7) also considers fragmented landscapes with dynamic (e.g. vegetation regrowth following land abandonment) or managed matrices (e.g. restored habitats following human intervention). In such landscapes, patch-centric patterns of occupancy (IBT) should gradually transition into those dominated by entire landscapes (HAH) given the role of matrix type in mediating species-area relationships (Freeman et al., 2018). Conversely, matrix 
523 habitat degradation would revert the emphasis back to prime habitat patches. Although

524 ameliorating the harshness of water matrices is virtually impossible, other hostile matrix

525 habitats, such as bauxite mining (Kennedy \& Marra, 2010), can be managed to enhance

526 functional connectivity among habitat patches (Fig. 7 in Villard \& Metzger, 2014). Finally,

527 we conclude that the most appropriate worldview in fragmentation ecology (IBT or HAH) is

528 not only context-dependent but also dynamic. Therefore, the best conservation strategy -

529 focusing on either the spatial arrangement of remaining habitat patches or the overall habitat

530 amount in the landscape - is neither static nor can be generalised to a wide spectrum of

531 landscape scenarios and taxonomic groups.

532 
Figure 1. (a) Location of the study area in central Brazilian Amazonia, indicated by a solid rectangle containing (b) the Balbina Hydroelectric Reservoir (BHR) landscape, showing the boundaries of the Uatumã Biological Reserve, a strictly-protected area safeguarding most of this landscape; (c) larger inset map showing the spatial distribution of the 33 surveyed islands; and (d) the 200-m buffer area (red polygon) around a mist-net line (white line) representing the local landscapes derived for the understorey insectivorous birds examined here. Photo credit: Eduardo M. Venticinque.

Figure 2. Possible conceptual relationships of the four empirical tests applied to determine whether either the island biogeography theory (IBT; graphs on the left) or the habitat amount hypothesis (HAH; graphs on the right) is the most appropriate theoretical framework to explain the number of understorey insectivorous bird species on forest islands within the Balbina Hydroelectric Reservoir in central Brazilian Amazonia.

Figure 3. Divergent species-area relationships for understorey insectivorous birds surveyed at 33 islands surrounded by either low $\left(r^{2}=0.598, p<0.001, n=15\right)$ or high $\left(r^{2}=0.547, p<\right.$ $0.001, n=18$ ) habitat amounts. Circle sizes scale to the landscape-scale habitat amount, with smaller and larger circles representing islands surrounded by either low or high habitat amounts, respectively. Note the different $z$-values for these two landscape scenarios ( $p=$ 0.009 ) and the base 10 logarithmic scales along both axes.

Figure 4. Species accumulation curves of understorey insectivorous birds for islands ordered according to either increasing (light grey circles, dashed line) or decreasing (dark grey circles, solid line) island size.

Figure 5. Species-area relationship for understorey insectivorous birds surveyed at 33 islands.

560 The white circle shows the extrapolated number of species (55.2) to a hypothetical island 561 containing the area $(+1)$ of all 33 surveyed islands combined $(7,841.4 \mathrm{ha})$, whereas the black circle shows the total number of species observed in this study $(59+1)$. Dashed lines show

563 the $95 \%$ confidence intervals of the predicted line. Note the base 10 logarithmic scales along 564 both axes. 
566 Figure 6. Sampling design established to control for the positive correlation between patch

567 size and habitat amount. The solid black circle correspondents to the local landscape defined

568 a priori (i.e. before the scale of effect is known). The dashed black circle corresponds to the 569 local landscape derived from a multi-scale analysis (i.e. post data analysis). The difference

570 between the two landscapes scales (solid and dashed black circles) implies that even a well-

571 designed study may fail to control for the collinearity between predictors. Figure modified

572 from Fahrig (2013).

573

574 Figure 7. Conceptual framework based on both the degree of matrix permeability and species

575 dispersal ability in determining whether the island biogeography theory (IBT) or the habitat

576 amount hypothesis (HAH) is the most appropriate guiding theoretical framework for

577 biodiversity studies in fragmented landscapes.

578 

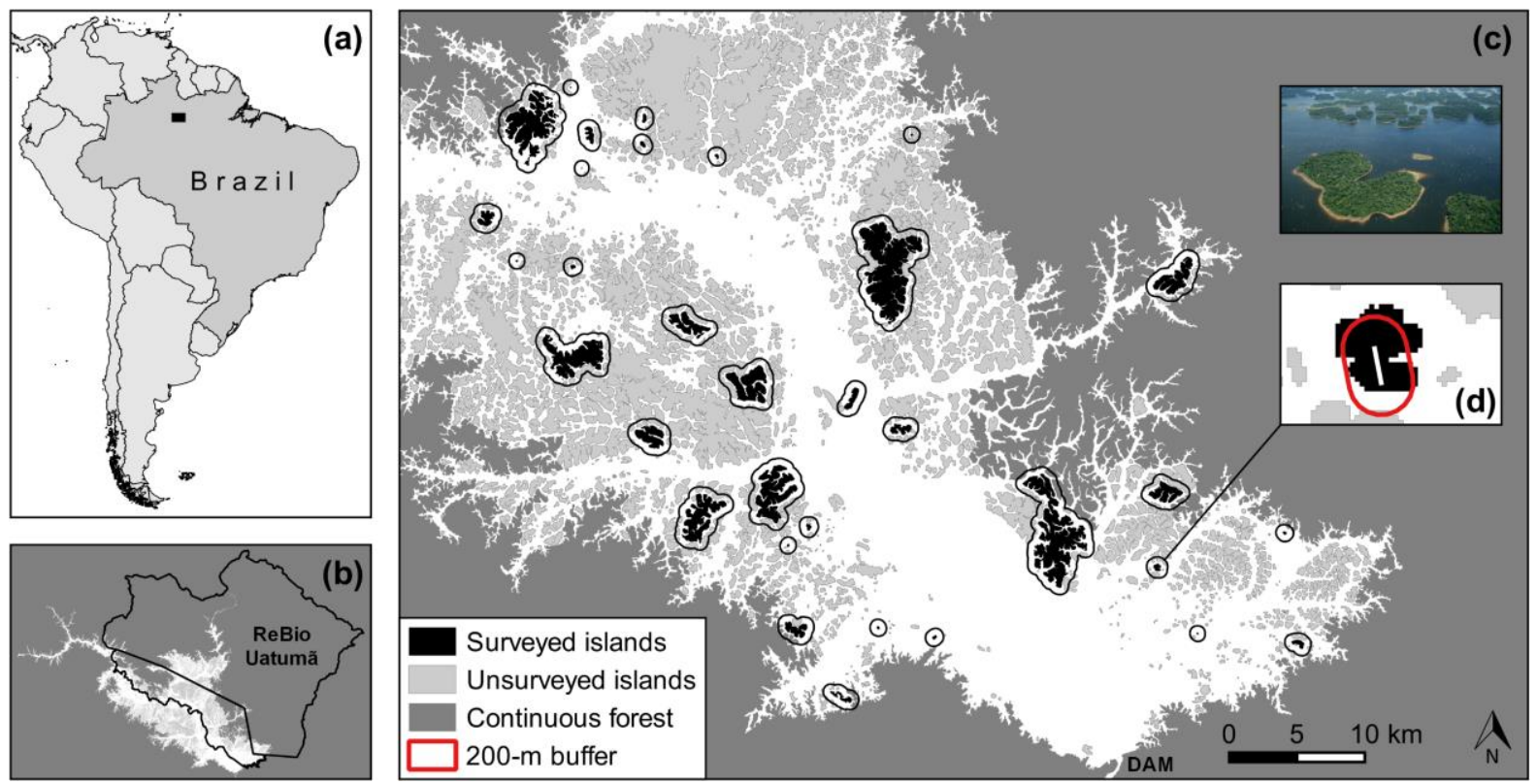

579

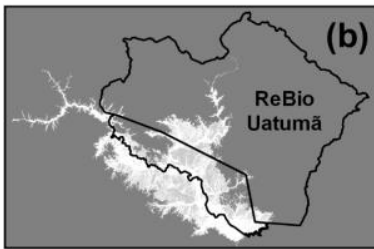

Surveyed island

Continuous forest

4

200-m buffer

580

Figure 1 


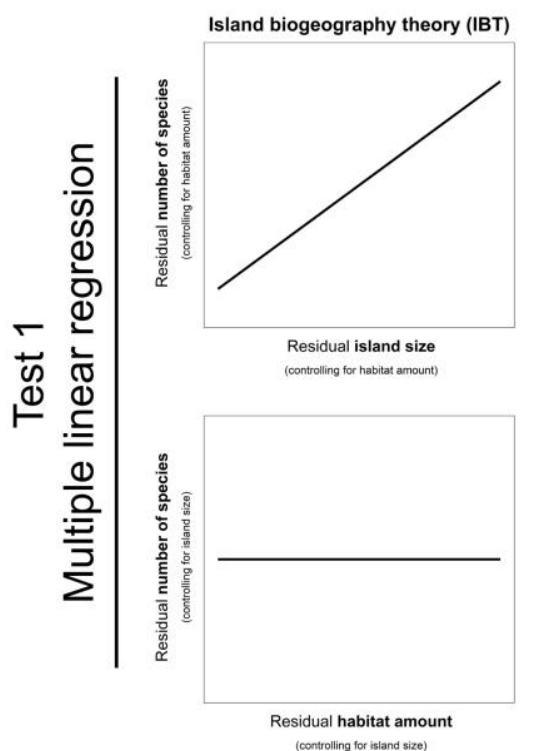

Habitat amount hypothesis (HAH)
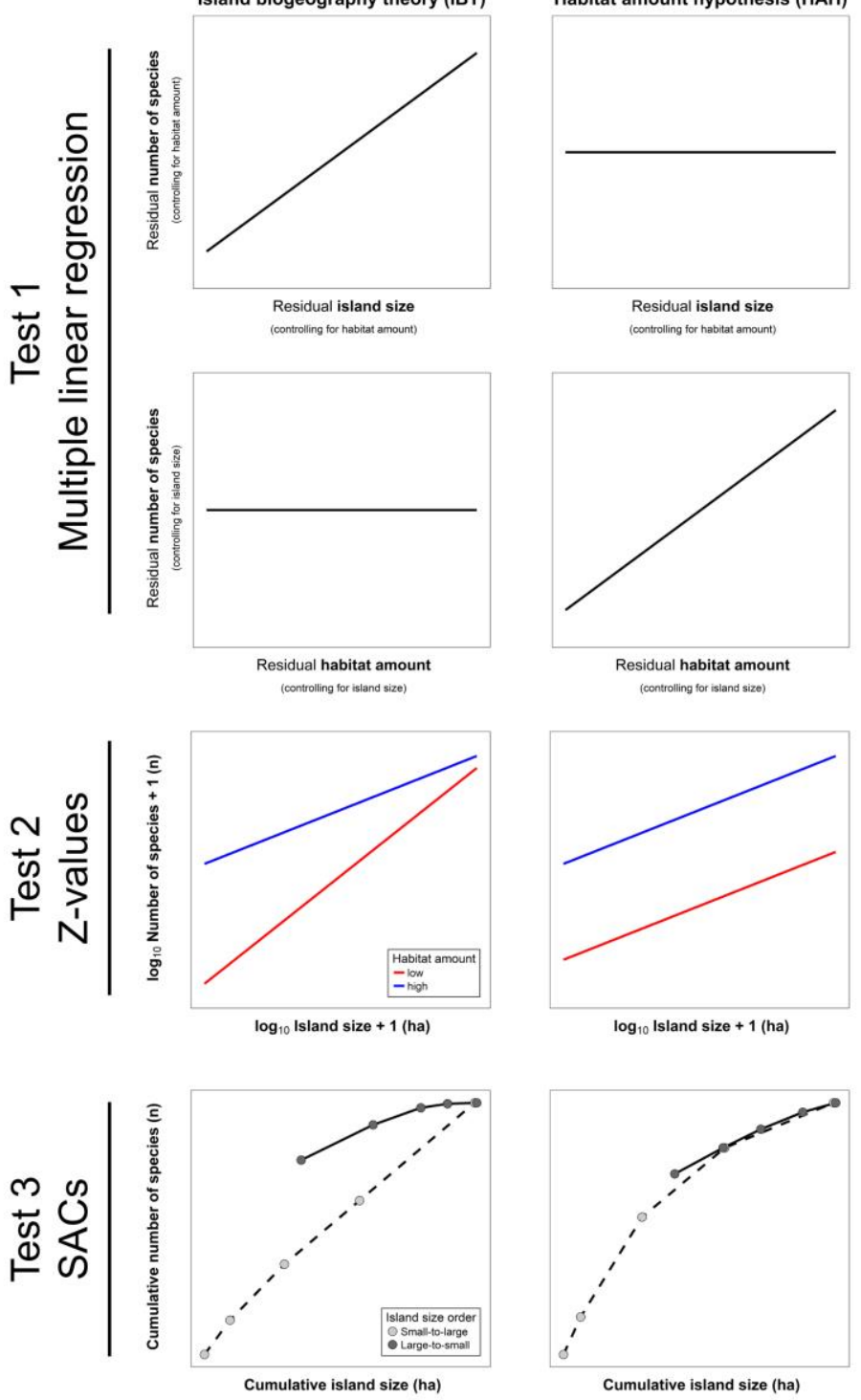

582
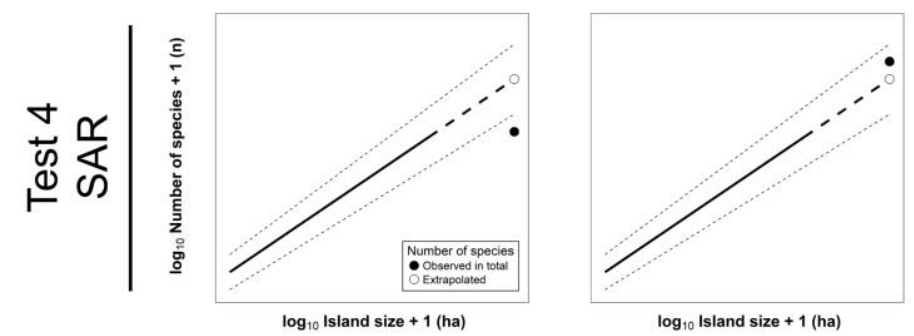

$583 \quad$ Figure 2 


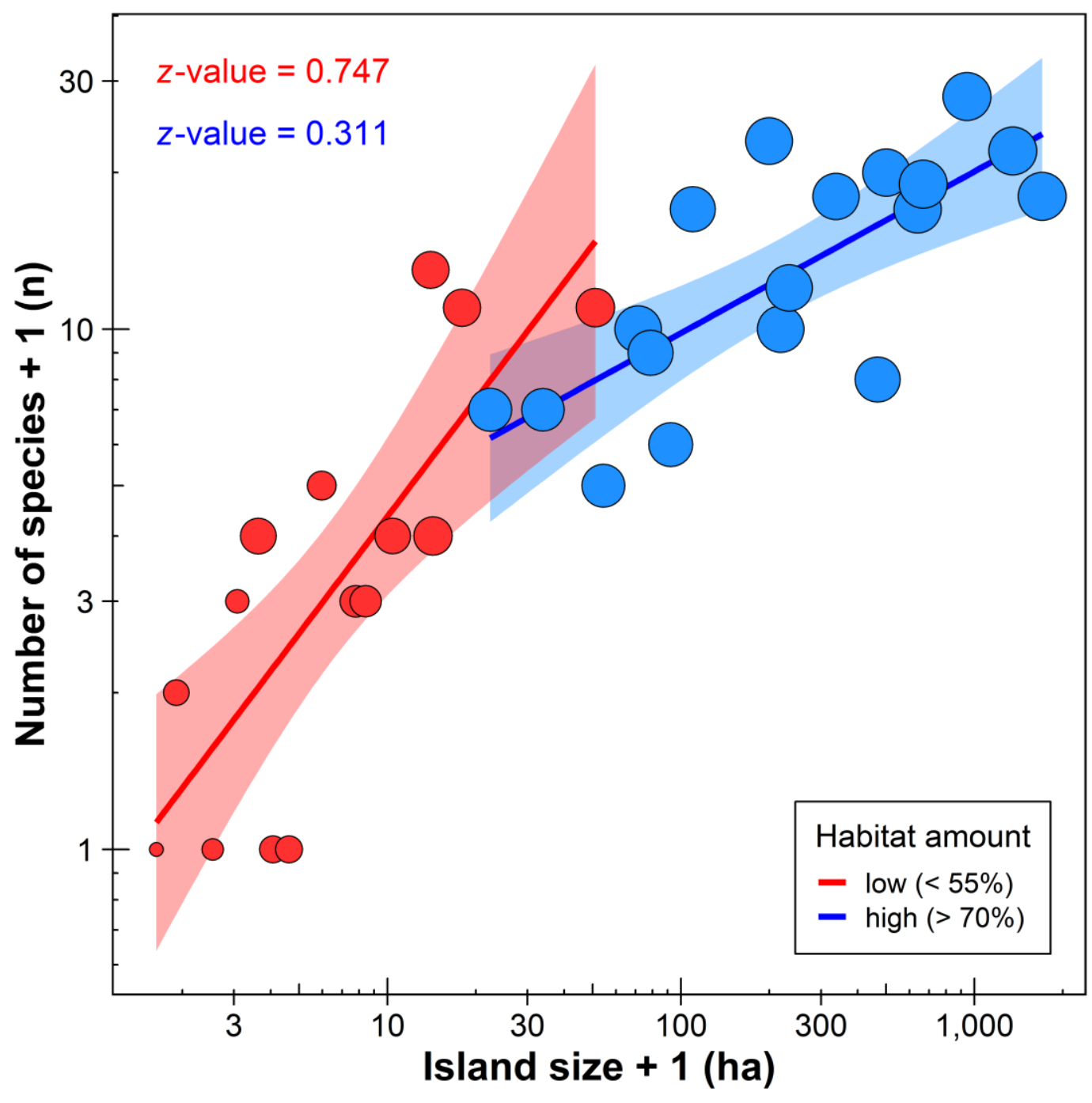

584

$585 \quad$ Figure 3

586 


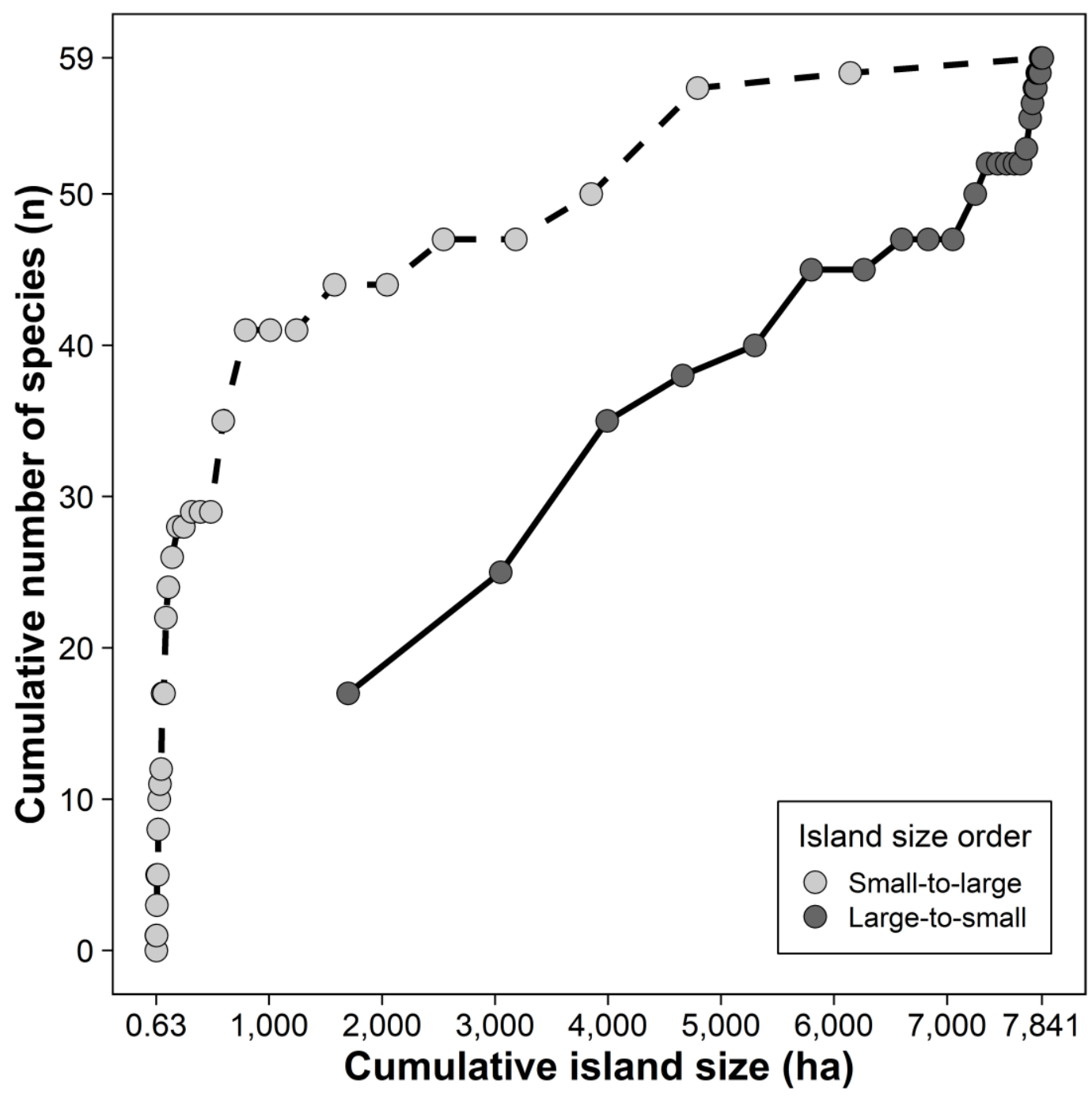

587

$588 \quad$ Figure 4

589 


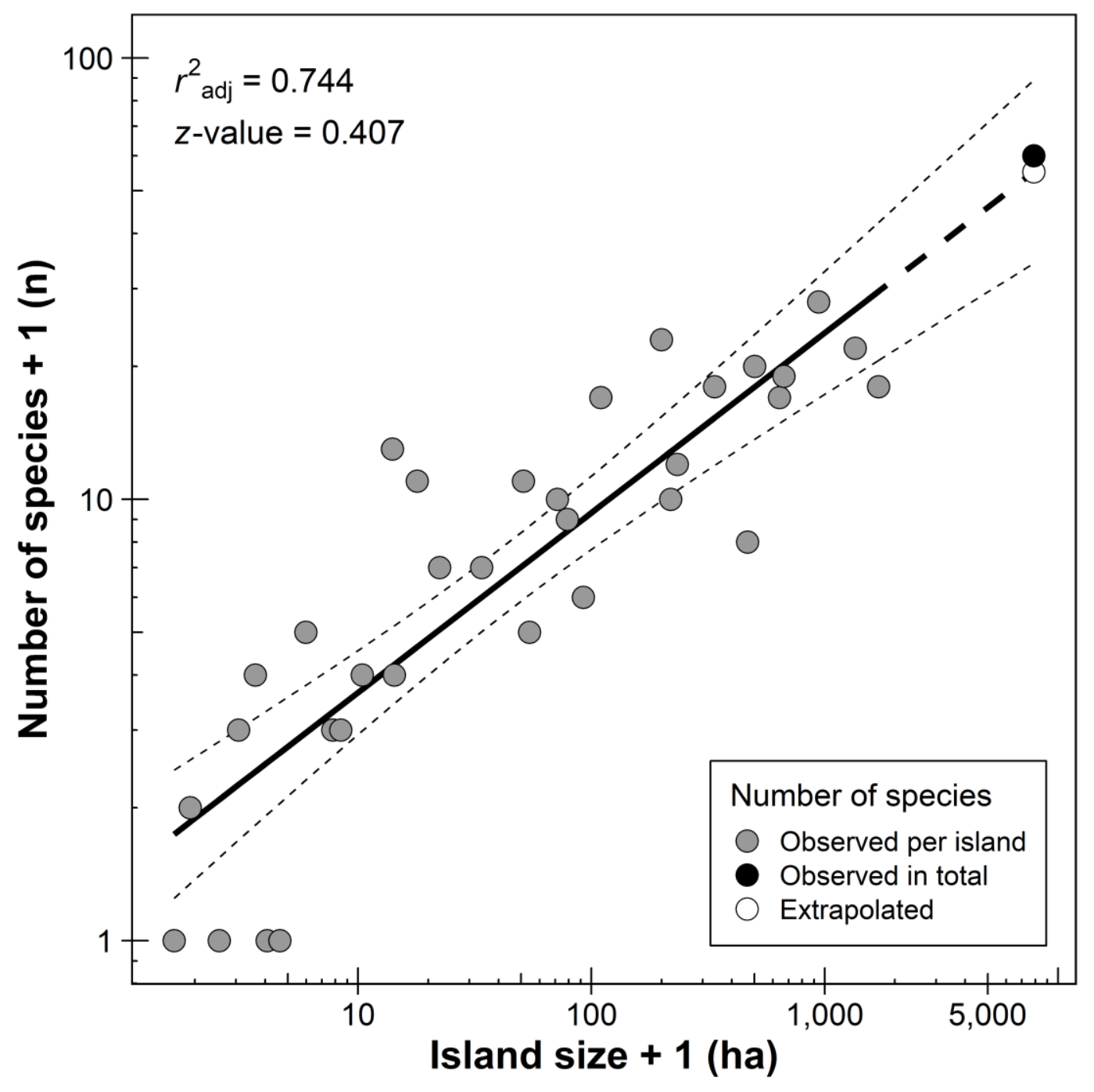

590

591 Figure 5

592 


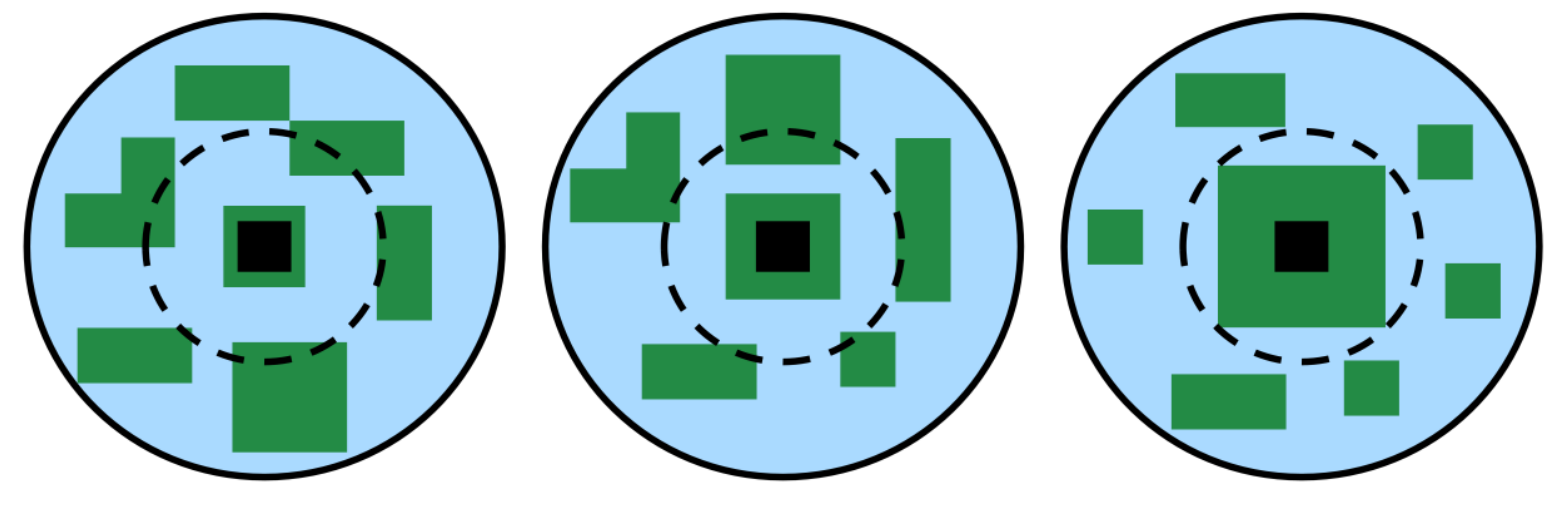

594 Figure 6 


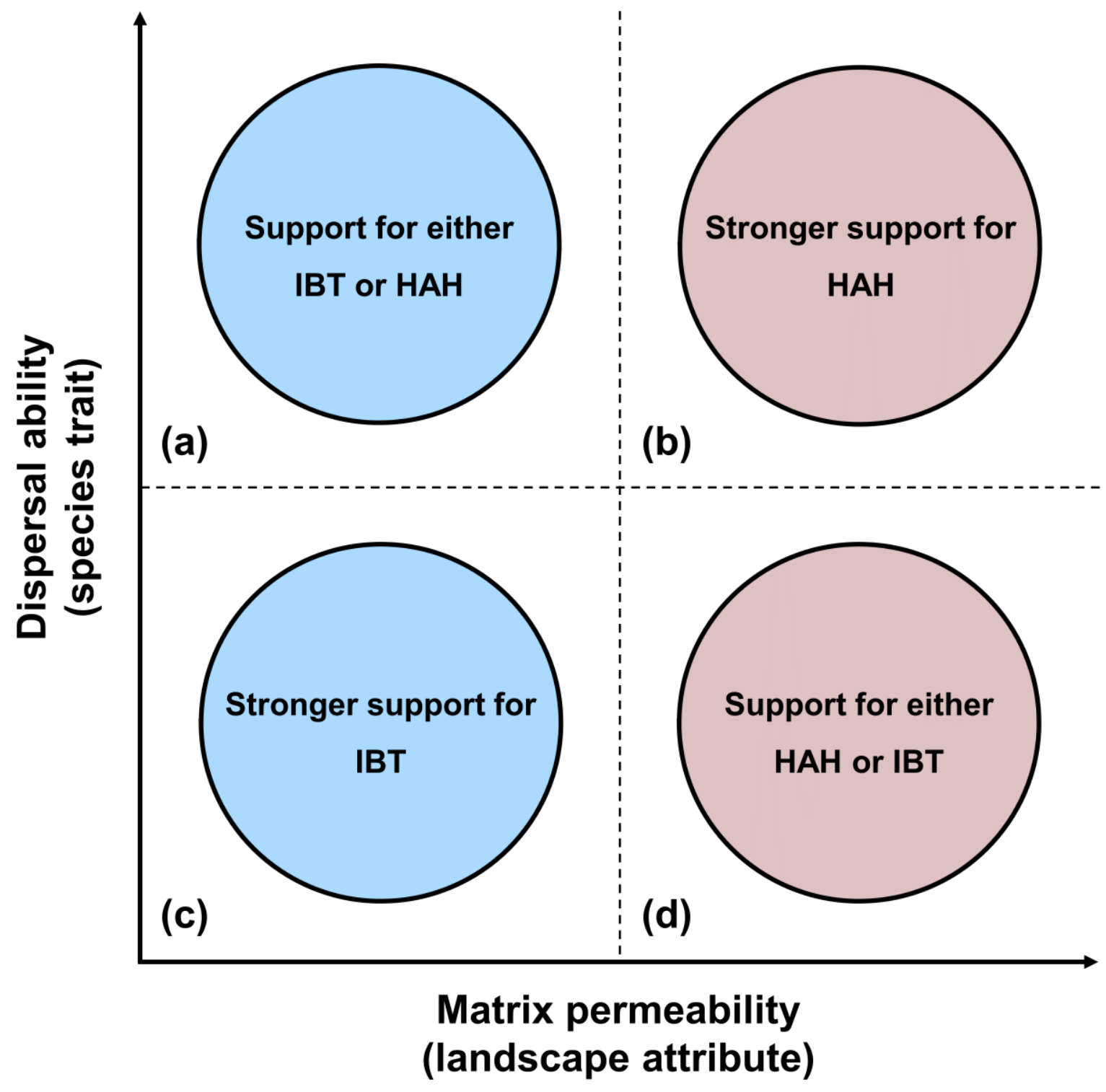

$597 \quad$ Figure 7 
Alvares, C.A., Stape, J.L., Sentelhas, P.C., Gonçalves, J.L. de M., \& Sparovek, G. (2013) Köppen's climate classification map for Brazil. Meteorologische Zeitschrift, 22, 711728.

Aurélio-Silva, M., Anciães, M., Henriques, L.M.P., Benchimol, M., \& Peres, C.A. (2016) Patterns of local extinction in an Amazonian archipelagic avifauna following 25 years of insularization. Biological Conservation, 199, 101-109.

Awade, M. \& Metzger, J.P. (2008) Using gap-crossing capacity to evaluate functional connectivity of two Atlantic rainforest birds and their response to fragmentation. Austral Ecology, 33, 863-871.

Báldi, A. (2008) Habitat heterogeneity overrides the species-area relationship. Journal of Biogeography, 35, 675-681.

Benchimol, M. \& Peres, C.A. (2015a) Edge-mediated compositional and functional decay of tree assemblages in Amazonian forest islands after 26 years of isolation. Journal of Ecology, 103, 408-420.

Benchimol, M. \& Peres, C.A. (2015b) Predicting local extinctions of Amazonian vertebrates in forest islands created by a mega dam. Biological Conservation, 187, 61-72.

Benchimol, M. \& Peres, C.A. (2015c) Widespread forest vertebrate extinctions induced by a mega hydroelectric dam in lowland Amazonia. PLOS ONE, 10, e0129818.

BirdLife International (2018) IUCN Red List for birds. Downloaded from http://www.birdlife.org in April 2018.

Blake, J.G. \& Loiselle, B.A. (2001) Bird assemblages in second-growth and old-growth forests, Costa Rica: Perspectives from mist nets and point counts. The Auk, 118, 304 326.

Castilho, C.V. de, Magnusson, W.E., de Araújo, R.N.O., Luizão, R.C.C., Luizão, F.J., Lima, A.P., \& Higuchi, N. (2006) Variation in aboveground tree live biomass in a central Amazonian forest: Effects of soil and topography. Forest Ecology and Management, 234, 85-96.

Dormann, C.F., Elith, J., Bacher, S., Buchmann, C., Carl, G., Carré, G., Marquéz, J.R.G., Gruber, B., Lafourcade, B., Leitão, P.J., Münkemüller, T., McClean, C., Osborne, P.E., Reineking, B., Schröder, B., Skidmore, A.K., Zurell, D., \& Lautenbach, S. (2013) Collinearity: a review of methods to deal with it and a simulation study evaluating their performance. Ecography, 36, 27-46.

Drucker, D.P., Costa, F.R.C., \& Magnusson, W.E. (2008) How wide is the riparian zone of small streams in tropical forests? A test with terrestrial herbs. Journal of Tropical Ecology, 24, 65-74.

Evju, M. \& Sverdrup-Thygeson, A. (2016) Spatial configuration matters: a test of the habitat amount hypothesis for plants in calcareous grasslands. Landscape Ecology, 31, 18911902.

Fahrig, L. (2003) Effects of habitat fragmentation on biodiversity. Annual Review of Ecology, Evolution, and Systematics, 34, 487-515. 
Fahrig, L. (2013) Rethinking patch size and isolation effects: the habitat amount hypothesis. Journal of Biogeography, 40, 1649-1663.

Fahrig, L. (2015) Just a hypothesis: A reply to Hanski. Journal of Biogeography, 42, 993994.

Fahrig, L. (2017) Ecological responses to habitat fragmentation per se. Annual Review of Ecology, Evolution, and Systematics, 48, 1-23.

Fearnside, P.M. (2016) Environmental and Social Impacts of Hydroelectric Dams in Brazilian Amazonia: Implications for the Aluminum Industry. World Development, 77, $48-65$.

Freeman, M.T., Olivier, P.I., \& van Aarde, R.J. (2018) Matrix transformation alters speciesarea relationships in fragmented coastal forests. Landscape Ecology, 33, 307-322.

Gavish, Y., Ziv, Y., \& Rosenzweig, M.L. (2012) Decoupling fragmentation from habitat loss for spiders in patchy agricultural landscapes. Conservation Biology, 26, 150-159.

Haddad, N.M., Gonzalez, A., Brudvig, L. a., Burt, M. a., Levey, D.J., \& Damschen, E.I. (2016) Experimental evidence does not support the Habitat Amount Hypothesis. Ecography, 125, 336-342.

Haila, Y. (2002) A conceptual genealogy of fragmentation research: From island biogeography to landscape ecology. Ecological Applications, 12, 321-334.

Hanski, I. (2015) Habitat fragmentation and species richness. Journal of Biogeography, 42, 989-993.

Jackson, H.B. \& Fahrig, L. (2012) What size is a biologically relevant landscape? Landscape Ecology, 27, 929-941.

Jackson, H.B. \& Fahrig, L. (2015) Are ecologists conducting research at the optimal scale? Global Ecology and Biogeography, 24, 52-63.

Jung, M. (2016) LecoS - A python plugin for automated landscape ecology analysis. Ecological Informatics, 31, 18-21.

Karr, J.R. (1981) Surveying birds in the tropics. Studies in Avian Biology, 6, 548-553.

Kennedy, C.M. \& Marra, P.P. (2010) Matrix mediates avian movements in tropical forested landscapes: Inference from experimental translocations. Biological Conservation, 143, 2136-2145.

Laurance, S.G.W., Stouffer, P.C., \& Laurance, W.F. (2004) Effects of road clearings on movement patterns of understory rainforest birds in central Amazonia. Conservation Biology, 18, 1099-1109.

Laurance, W.F. (2008) Theory meets reality: How habitat fragmentation research has transcended island biogeographic theory. Biological Conservation, 141, 1731-1744.

Lees, A.C. \& Peres, C.A. (2009) Gap-crossing movements predict species occupancy in Amazonian forest fragments. Oikos, 118, 280-290.

Legendre, P. \& Legendre, L. (1998) Numerical Ecology. Elsevier Science, Amsterdam, The Netherlands.

Lima, J.R., Galatti, U., Lima, C.J., Fáveri, S.B., Vasconcelos, H.L., \& Neckel-Oliveira, S. 

(2015) Amphibians on Amazonian land-bridge islands are affected more by area than isolation. Biotropica, 47, 369-376.

Lomolino \& Weiser (2001) Towards a more general species-area relationship: diversity on all islands, great and small. Journal of Biogeography, 28, 431-445.

Lovei, G.L., Magura, T., Tothmeresz, B., \& Kodobocz, V. (2006) The influence of matrix and edges on species richness patterns of ground beetles (Coleoptera: Carabidae) in habitat islands. Global Ecology and Biogeography, 15, 283-289.

MacArthur, R.H. \& Wilson, E.O. (1967) The Theory of Island Biogeography. Princeton University Press, Princeton, New Jersey, USA.

MacDonald, Z.G., Anderson, I.D., Acorn, J.H., \& Nielsen, S.E. (2018) Decoupling habitat fragmentation from habitat loss: butterfly species mobility obscures fragmentation effects in a naturally fragmented landscape of lake islands. Oecologia, 186, 11-27.

Matthews, T.J., Guilhaumon, F., Triantis, K.A., Borregaard, M.K., \& Whittaker, R.J. (2016) On the form of species-area relationships in habitat islands and true islands. Global Ecology and Biogeography, 25, 847-858.

Melo, G.L., Sponchiado, J., Cáceres, N.C., \& Fahrig, L. (2017) Testing the habitat amount hypothesis for South American small mammals. Biological Conservation, 209, 304-314.

Moore, R.P., Robinson, W.D., Lovette, I.J., \& Robinson, T.R. (2008) Experimental evidence for extreme dispersal limitation in tropical forest birds. Ecology Letters, 11, 960-968.

Morante-Filho, J.C., Faria, D., Mariano-Neto, E., \& Rhodes, J. (2015) Birds in anthropogenic landscapes: The responses of ecological groups to forest loss in the Brazilian Atlantic Forest. PLOS ONE, 10, e0128923.

Munguía-Rosas, M.A. \& Montiel, S. (2014) Patch size and isolation predict plant species density in a naturally fragmented forest. PLOS ONE, 9, e111742.

Palmeirim, A.F., Vieira, M.V., \& Peres, C. A. (2017) Non-random lizard extinctions in landbridge Amazonian forest islands after 28 years of isolation. Biological Conservation, 214, 55-65.

Powell, L.L., Cordeiro, N.J., \& Stratford, J. A. (2015) Ecology and conservation of avian insectivores of the rainforest understory: A pantropical perspective. Biological Conservation, 188, 1-10.

Powell, L.L., Stouffer, P.C., \& Johnson, E.I. (2013) Recovery of understory bird movement across the interface of primary and secondary Amazon rainforest. The Auk, 130, 459468.

Prevedello, J.A. \& Vieira, M.V. (2010) Does the type of matrix matter? A quantitative review of the evidence. Biodiversity and Conservation, 19, 1205-1223.

Prugh, L.R., Hodges, K.E., Sinclair, A.R.E., \& Brashares, J.S. (2008) Effect of habitat area and isolation on fragmented animal populations. Proceedings of the National Academy of Sciences, 105, 20770-20775.

QGIS Development Team (2018) QGIS Geographic Information System. Version 2.14.22. Open Source Geospatial Foundation Project. URL http://qgis.osgeo.org.

Quinn, J.F. \& Harrison, S.P. (1988) Effects of habitat fragmentation and isolation on species 
Rabelo, R.M., Bicca-Marques, J.C., Aragón, S., \& Nelson, B.W. (2017) Are fluvial islands "real" islands for arboreal mammals? Uncovering the effect of patch size under the species-area relationship. Journal of Biogeography, 1-11.

Rosenzweig, M.L. (1995) Species Diversity in Space and Time. Cambridge University Press, Cambridge, UK.

Santos, A.M.C., Whittaker, R.J., Triantis, K.A., Borges, P.A. V, Jones, O.R., Quicke, D.L.J., \& Hortal, J. (2010) Are species-area relationships from entire archipelagos congruent with those of their constituent islands? Global Ecology and Biogeography, 19, 527-540.

Scheiner, S.M. (2003) Six types of species-area curves. Global Ecology and Biogeography, 12, 441-447.

Schietti, J., Emilio, T., Rennó, C.D., Drucker, D.P., Costa, F.R.C., Nogueira, A., Baccaro, F.B., Figueiredo, F., Castilho, C. V., Kinupp, V., Guillaumet, J.-L., Garcia, A.R.M., Lima, A.P., \& Magnusson, W.E. (2014) Vertical distance from drainage drives floristic composition changes in an Amazonian rainforest. Plant Ecology \& Diversity, 7, 241253.

Seibold, S., Bässler, C., Brandl, R., Fahrig, L., Förster, B., Heurich, M., Hothorn, T., Scheipl, F., Thorn, S., \& Müller, J. (2017) An experimental test of the habitat-amount hypothesis for saproxylic beetles in a forested region. Ecology, 98, 1613-1622.

Sekercioglu, C.H., Ehrlich, P.R., Daily, G.C., Aygen, D., Goehring, D., \& Sandi, R.F. (2002) Disappearance of insectivorous birds from tropical forest fragments. Proceedings of the National Academy of Sciences, 99, 263-267.

Storck-Tonon, D. \& Peres, C. A. (2017) Forest patch isolation drives local extinctions of Amazonian orchid bees in a 26 years old archipelago. Biological Conservation, 214, 270-277.

Stouffer, P.C., Bierregaard, R.O., Strong, C., \& Lovejoy, T.E. (2006) Long-term landscape change and bird abundance in Amazonian rainforest fragments. Conservation Biology, 20, 1212-1223.

Stouffer, P.C., Johnson, E.I., Bierregaard, R.O., \& Lovejoy, T.E. (2011) Understory bird communities in Amazonian rainforest fragments: Species turnover through 25 years post-isolation in recovering landscapes. PLOS ONE, 6, e20543.

Torrenta, R. \& Villard, M.-A. (2017) A test of the habitat amount hypothesis as an explanation for the species richness of forest bird assemblages. Journal of Biogeography, 44, 1791-1801.

Villard, M.-A. \& Metzger, J.P. (2014) Beyond the fragmentation debate: a conceptual model to predict when habitat configuration really matters. Journal of Applied Ecology, 51, 309-318.

Walter, S.T., Browne, L., Freile, J., Olivo, J., González, M., \& Karubian, J. (2017) Landscape-level tree cover predicts species richness of large-bodied frugivorous birds in forest fragments. Biotropica, 49, 838-847.

Wiens, J.A. (2008) Habitat fragmentation: Island v landscape perspectives on bird conservation. Ibis, 137, S97-S104. 
Wilman, H., Belmaker, J., Simpson, J., de la Rosa, C., Rivadeneira, M.M., \& Jetz, W. (2014) EltonTraits 1.0: Species-level foraging attributes of the world's birds and mammals. Ecology, 95, 2027-2027.

Yaacobi, G., Ziv, Y., \& Rosenzweig, M.L. (2007) Habitat fragmentation may not matter to species diversity. Proceedings of the Royal Society B: Biological Sciences, 274, 2409 2412.

\section{BIOSKETCHES}

Anderson Saldanha Bueno is a PhD student at the School of Environmental Sciences, University of East Anglia, UK. Since 2008, he has been working on avian community ecology in Brazilian Amazonia, focusing on species distributions along environmental gradients. His doctoral research seeks to understand patterns of species assembly and extinction risk in experimental island landscapes.

Carlos A. Peres is a Brazilian-born Professor of Tropical Conservation Biology at the University of East Anglia with 35 years of field and modelling experience on a wide spectrum of research topics on Neotropical forest wildlife ecology and conservation. Much of his research program focuses on the disturbance ecology of Amazonian forests.

Author contributions: A.S.B. and C.A.P. conceived the ideas; A.S.B. collected the field data; A.S.B. analysed the data; and A.S.B. wrote the manuscript with substantial inputs from C.A.P. 